\title{
Increased plasma triglycerides, cholesterol and apolipoprotein E during prolonged fasting in normal subjects
}

\author{
Arieh Markel, J. Gerald Brook and Michael Aviram \\ Lipid Research Unit, Rambam Medical Center and Faculty of Medicine, Technion-Israel Institute of Technology, \\ Haifa, Israel
}

\begin{abstract}
Summary: Plasma lipid and high density lipoprotein (HDL) levels were studied in 20 normal, healthy, non-obese males while fasting ( $150 \mathrm{kcal} / \mathrm{d}$ with free intake of water) for $6 \mathrm{~d}$ in a hunger strike. Plasma triglyceride and cholesterol levels were increased by $18 \%$ after $6 \mathrm{~d}$ of fasting. HDL-cholesterol concentration was not significantly changed for $4 \mathrm{~d}$, but decreased by $22 \%$ after $6 \mathrm{~d}$. Platelet aggregation induced by adenosine diphosphate (ADP) or collagen after $6 \mathrm{~d}$ of fasting was in the normal range. In 3 subjects fasted for $9 \mathrm{~d}$, a complete plasma lipoprotein analysis was done. Very low and low density lipoprotein (VLDL and LDL) levels were elevated, whereas HDL was reduced after $9 \mathrm{~d}$ of fasting. On isoelectric focusing analysis, a marked reduction in apolipoprotein (apo) E concentration in both VLDL and HDL was noted. Liver function tests showed a reduction in hepatic enzyme activity; and since apo $E$ is of hepatic origin also, we suggest that long fasting inhibits liver function in normal subjects.
\end{abstract}

\section{Introduction}

The effect of fasting or low-calorie intake on plasma lipid levels is different in obese and non-obese subjects. In obese subjects, fasting results in a reduction in plasma triglyceride and cholesterol concentrations (Jackson, 1969; Sorbis et al., 1981; Wolf \& Grundy, 1983; Olefsky et al., 1974; Zimmerman et al., 1984; Yeshurun et al., 1982). The results of high density lipoprotein (HDL)-cholesterol changes are inconsistent (Streja et al., 1980; Wechsler et al., 1981; Brownell \& Stunkard, 1981). In normal non-obese subjects, however, fasting results in an elevation of plasma lipid levels (Stout et al., 1976; Ende, 1962; Consolazio et al., 1967; Fainaro \& Schaffer, 1984). The changes in plasma lipids are reflected by similar changes in very low density and low density lipoprotein (VLDL and LDL) levels (Sorbis et al., 1981; Wolf \& Grundy, 1983; Zimmerman et al., 1984; Yeshurun et al., 1982; Streja et al., 1980; Brownell \& Stunkard, 1981; Fainaro \& Schaffer, 1985), while the results for HDL levels after fasting in non-obese subjects are inconsistent (Zimmerman et al., 1984; Yeshurun et al., 1982; Streja et al., 1980; Wechsler et al., 1981; Brownell \& Stunkard, 1981).

The present study was undertaken during a national physicians' hunger strike, in which they consumed $0-150 \mathrm{kcal} / \mathrm{d}$ derived from sweetened water for up to

Correspondence: M. Aviram D.Sc., Lipid Research Unit Rambam Medical Center, Haifa 35254, Israel.

Accepted: 25 October 1984 nine days. We investigated plasma lipid and lipoprotein concentration and composition in 20 normal males during the fasting period. Since plasma lipoproteins affect platelet function (Aviram et al., 1981; Aviram \& Brook, 1982, 1983a, 1983b; Brook et al., 1983), we also determined platelet aggregation after long fasting.

\section{Subjects and methods}

Twenty male physicians starting a hunger strike volunteered for this study. All subjects were normolipidaemic, non-obese, healthy and taking no medications. Diabetes mellitus, thyroid, kidney and liver disease were excluded by appropriate laboratory tests. Insulin and thyroid hormones were found to be in the normal range both before and after fasting. All subjects were drinking plain water or sweetened water freely with a maximum of $150 \mathrm{kcal} / \mathrm{d}$ for six days, except for 3 subjects who continued fasting over $9 \mathrm{~d}$. All subjects continued to attend to daily activities.

Blood was drawn at $08.00 \mathrm{~h}$ into disodium EDTA $(1 \mathrm{mg} / \mathrm{ml}$ final concentration), and plasma was separated by centrifugation at $2000 \times g$ for $10 \mathrm{~min}$ at $4^{\circ} \mathrm{C}$. For platelet analysis, blood was drawn into $3.8 \%$ sodium citrate $(v / v=9 / 1)$. HDL-cholesterol concentration was analysed after precipitation of VLDL and LDL from the plasma by heparin and manganous chloride (Warnick \& Albers, 1978). 


\section{Preparation of lipoproteins}

Plasma lipoproteins were separated by discontinuous density gradient ultracentrifugation (Aviram, 1983). The density of $4 \mathrm{ml}$ samples of plasma was raised to $1.250 \mathrm{~g} / \mathrm{ml}$ with potassium bromide. Four $\mathrm{ml}$ of a solution of density $1.084 \mathrm{~g} / \mathrm{ml}$ were then carefully laid over the plasma sample, followed by $4 \mathrm{ml}$ of sodium chloride $(\rho=1.006 \mathrm{~g} / \mathrm{ml})$. Ultracentrifugation was performed in an SW-41 rotor in a Beckman L2-65B preparative ultracentrifuge at $35,000 \times g$ for $48 \mathrm{~h}$ at $4^{\circ} \mathrm{C}$. Lipoproteins (VLDL, LDL and HDL) and lipoprotein-deficient plasma (LPDP) were then carefully removed and dialysed extensively against $150 \mathrm{mmol} / \mathrm{l}$ sodium chloride in $1 \mathrm{mmol} /$ EDTA, pH 8.6. The purity of each fraction was analysed by cellulose acetate electrophoresis, Ouchterlony double immunodiffusion and immunoelectrophoresis for all the experiements. The lipoproteins were pure and free of other plasma proteins. Lipoprotein-protein concentration was determined using the procedure of Lowry et al. (1951). The cholesterol and triglyceride content of plasma and of each lipoprotein was determined by enzymatic methods (Zak, 1977; Ziegenhorn, 1975) on a centrifugal fast analyser (Electro-Nucleonics, Gemsaec, Fairfield, New Jersey).

\section{Polyacrylamide gel isoelectric focusing (PAGE)}

Plasma lipoproteins were delipidated using $4.2 \mathrm{~mol} / 1$ of 1,1,3,3-tetramethylurea, and $100 \mu \mathrm{g}$ of protein was applied to each gel $(8 \times 0.6 \mathrm{~cm})$. Each sample was treated with $50 \mathrm{mmol} / 1$ dithiotreitol, $0.05 \%$ Triton X-

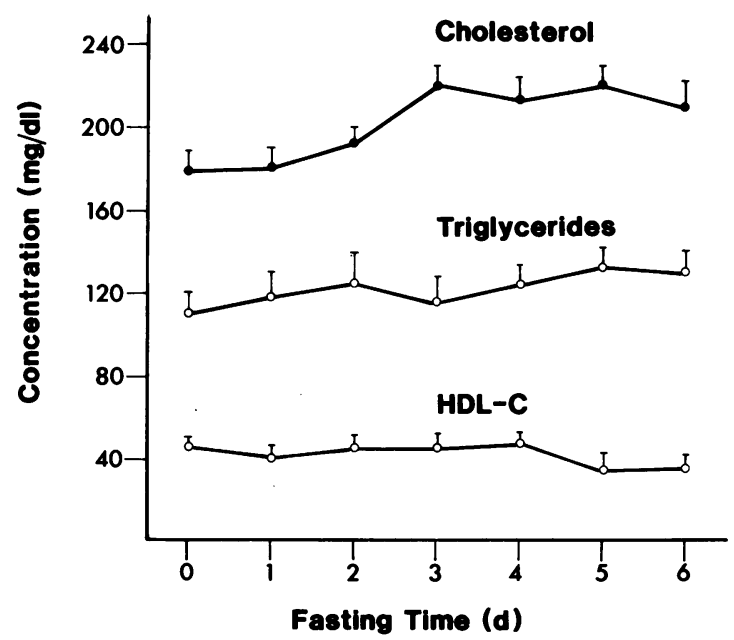

Figure 1 Time-course study of plasma cholesterol, triglyceride, and HDL-cholesterol concentration during fasting in normal, healthy subjects. Each point represents mean \pm s.e.mean of 20 subjects. HDL-C $=$ high density lipoprotein-cholesterol.
100 and $5 \%$ sucrose solution (final concentration). Gels for PAGE were prepared with $6 \mathrm{~mol} / 1 \mathrm{urea}, 7.5 \%$ acrylamide and $0.2 \%$ bisacrylamide, using $3 \%$ ampholine (Bio-Lyte $4 / 6$ for HDL and 3/10 for VLDL, Bio-Rad Laboratories, Richmond, California), $0.06 \%$ ammonium persulphate and $0.006 \%$ tetramethylethylenediamine.

The anode solution was $0.01 \mathrm{~mol} / 1$ phosphoric acid and the cathode solution, $0.2 \mathrm{~mol} / 1$ sodium chloride. The sample $(200 \mu \mathrm{l})$ was applied onto the gel through the electrolyte solution, and PAGE was performed at $250 \mathrm{~V}$ for $18 \mathrm{~h}$ at $4^{\circ} \mathrm{C}$ (Warnick et al., 1979). To determine the $\mathrm{pH}$ gradient, $2 \mathrm{~mm}$ segments of unfixed and unstained gels were transferred into a glass tube containing $2 \mathrm{ml}$ of distilled water, and the $\mathrm{pH}$ of each segment was determined after $24 \mathrm{~h}$ at room temperature. The gels were simultaneously fixed and stained for $2 \mathrm{~h}$ at $45^{\circ} \mathrm{C}$ with $0.25 \%$ Coomassie blue G in $50 \%$ methanol and $10 \%$ acetic acid. Destaining was performed using volumes of acetic acid:methanol: water of $1: 3: 5$, respectively.

\section{Rocket electro-immunophoresis of plasma apolipoproteins}

Plasma and lipoprotein levels of apolipoproteins B and A-I were determined by rocket electro-immunoassay, adapting the technique of Laurell (1966) Appropriate standards for plasma and lipoprotein were included in each run.

\section{Platelet aggregation}

Platelet-rich plasma (PRP) was prepared from citrated whole blood by low-speed centrifugation at $200 \times g$ for $10 \mathrm{~min}$ at $23^{\circ} \mathrm{C}$. Platelet aggregation was studied in a dual aggregometer (Chrono-Log Corporation, Havertown, Pennsylvania) according to the method of Born (1969). Adenosine diphosphate (ADP; $5 \mu \mathrm{mol} / \mathrm{l}$ ) and collagen $(1 \mu \mathrm{g} / \mathrm{ml})$ were used as the aggregating agents. The per cent transmittance of PRP was recorded as 0 and that of its appropriate blank (platelet-poor plasma) as 100. Results of platelet aggregation were expressed as the percentage of aggregation amplitude.

\section{Results}

Plasma cholesterol and triglyceride concentrations were found to increase during fasting by $18 \%$ after $6 \mathrm{~d}$ (Figure 1). The main increment in plasma cholesterol was between the first and third days of fasting, whereas plasma triglyceride concentration was elevated along the fasting period.

HDL-cholesterol did not change significantly for $4 \mathrm{~d}$ and then dropped by $22 \%$ on days 5 and 6 of fasting (Figure 1). 
Table I Effect of long fasting on plasma lipoprotein concentration in three normal, healthy, non-obese male subjects

Subject Plasma VLDL LDL HDL

\begin{tabular}{llllll}
\hline Cholesterol (mg/dl) & & & & & \\
Basal & 1 & 178 & 20 & 101 & 57 \\
& 2 & 168 & 23 & 100 & 45 \\
Fasted & 3 & 169 & 22 & 102 & 45 \\
& 1 & 200 & 38 & 113 & 49 \\
Triglycerides (mg/dl) & 2 & 195 & 39 & 111 & 37 \\
Basal & 1 & 197 & 38 & 127 & 32 \\
& 2 & 108 & 70 & 21 & 17 \\
Fasted & 109 & 67 & 27 & 15 \\
& 3 & 103 & 60 & 29 & 14 \\
& 1 & 129 & 83 & 33 & 13 \\
Protein (mg/dl) & 2 & 133 & 81 & 41 & 11 \\
Basal & 3 & 131 & 74 & 47 & 10 \\
& 1 & & 17 & 86 & 162 \\
Fasted & 2 & & 20 & 80 & 190 \\
& 3 & & 21 & 73 & 216 \\
& 1 & & 21 & 91 & 148 \\
& 2 & & 23 & 90 & 164 \\
& 3 & & 27 & 81 & 152 \\
\hline
\end{tabular}
fast.

Results are shown on day 1 (basal) and day 9 (fasted) of

Three subjects continued fasting for $9 \mathrm{~d}$, and we analysed their plasma lipoprotein pattern after 1 and 9 days of fasting. Table 1 shows that the elevation in both plasma cholesterol and triglyceride levels was the result of increased levels of VLDL and LDL. Similar elevation was found for VLDL and LDL protein concentration. HDL levels, on the other hand, markedly reduced after $9 \mathrm{~d}$ of fasting (Table I). Analysis of the apolipoproteins from HDL and VLDL revealed that after $9 \mathrm{~d}$ of fasting there was a marked reduction in the apolipoprotein (apo) E concentration in both lipoproteins in comparison to the situation before beinning the fast (Figure 2). Plasma apo A-I reduced in the three subjects by 18,10 and $17 \%$, whereas plasma apo $B$ concentration increased by 21,39 and $17 \%$ after $9 \mathrm{~d}$ of fasting.

Analysis of compliance to fasting revealed a significant reduction in body weight, with elevated uric acid concentration (Table II). The levels of the liver enzymes glutamic-oxaloacetic transaminase (GOT) and alkaline phosphatase, however, decreased during the fasting. No significant changes were observed in blood electrolyte, urea, glucose and creatinine concentrations. Platelet aggregation induced by ADP $(5 \mathrm{mmol} / \mathrm{l})$ and collagen $(1 \mu \mathrm{g} / \mathrm{ml})$ after $6 \mathrm{~d}$ of fasting was $48 \pm 6$ and $77 \pm 9 \%$, respectively, which is in the normal range as found before fasting ( $42 \pm 7$ and $72 \pm 10 \%$, respectively, $n=10$ ).

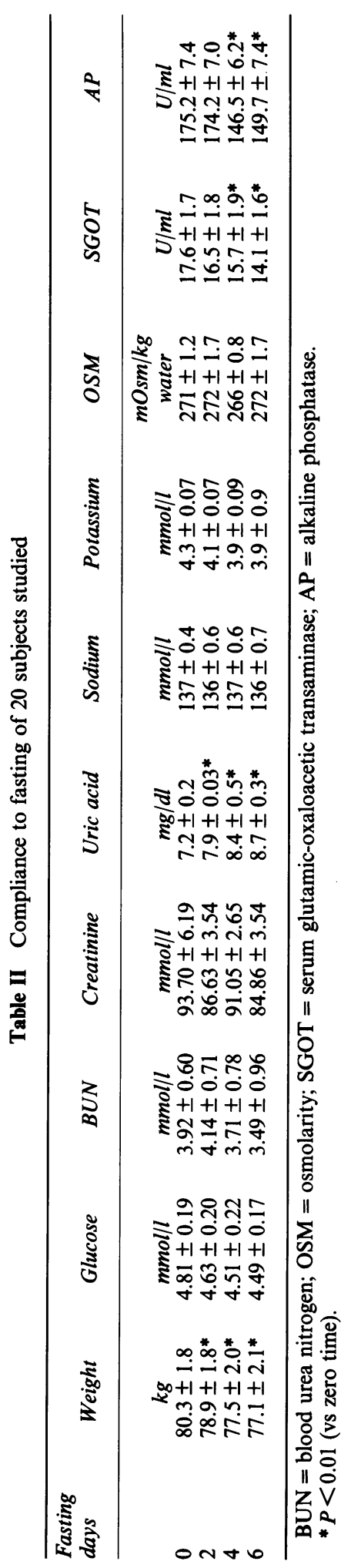




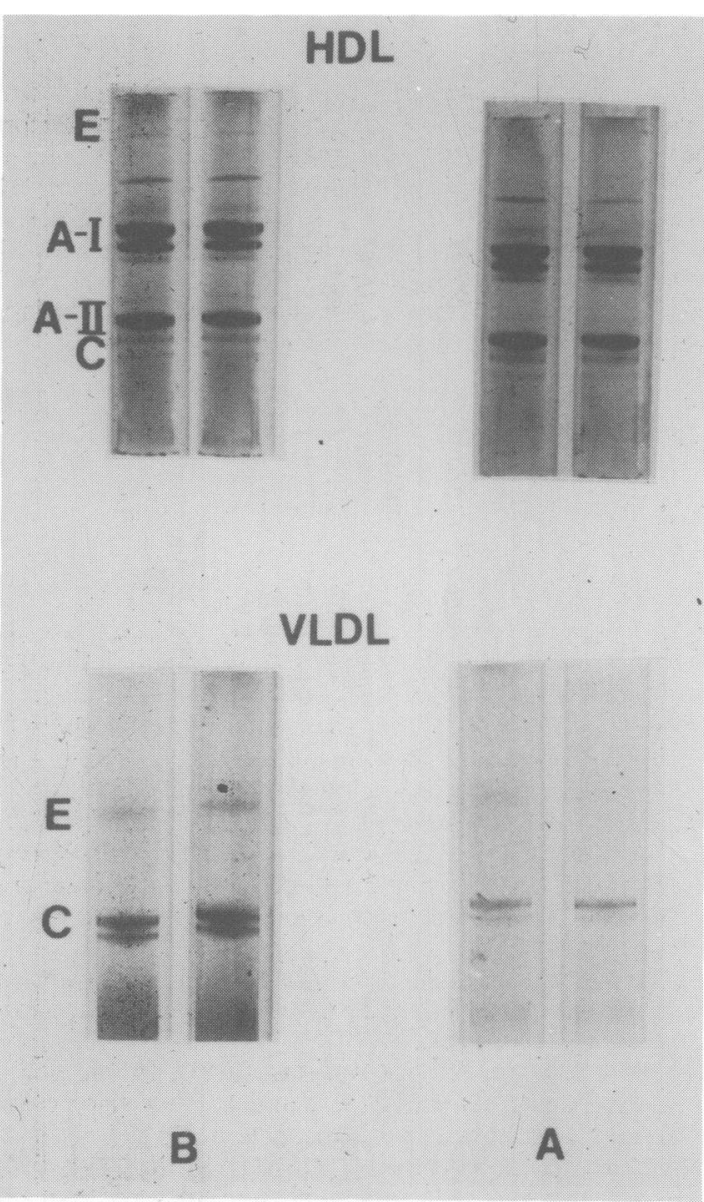

Figure 2 Polacrylamide gel isoelectric focusing analysis of HDL and VLDL apolipoproteins. Seventy-five $\mu \mathrm{g}$ of lipoprotein-protein were loaded onto each gel. Lipoproteins from 2 subjects are shown. $\mathrm{B}=$ before fasting (after $12 \mathrm{~h}$ of fast); $\mathrm{A}=$ after fasting ( 9 days of fast); E, A-I, A-II, and C = apolipoproteins.

\section{Discussion}

This study demonstrates that fasting for up to $9 \mathrm{~d}$ induces increments in plasma triglyceride and cholesterol concentrations, as well as enhanced levels of VLDL and LDL, in normal, non-obese, healthy male subjects (Figure 1 and Table I). This is in contrast to the hypolipidaemic effect observed in obese subjects (Jackson, 1969; Sorbis et al., 1981; Wolf \& Grundy, 1983; Olefsky et al., 1974; Zimmerman et al., 1984; Yeshurun et al., 1982).

A similar pattern of plasma triglyceride elevation in non-obese subjects has been observed by others, where it was followed by an increased availability of fatty acids to the liver, decreased plasma insulin, increased plasma glucagon and peripheral insulin resistance $\stackrel{0}{0}$ (Fainaro \& Schaffer, 1984; Rubin \& Aladjem, 1954; 气 Newman \& Brodows, 1983). Increased free fatty acid availability to the liver results in increased VLDL $\stackrel{\mathcal{D}}{\mathcal{D}}$ synthesis, and thus all VLDL components increased $c$. after fasting (Table I). The increased plasma choles- $\vec{F}$ terol level after fasting is a result of elevation in both $\stackrel{5}{+}$ VLDL and LDL concentrations. Increased cholesterol biosynthesis upon fasting or cholesterol release $\frac{\bar{F}}{\overline{0}}$ from cell breakdown (Swaner \& Connor, 1975; Diet-

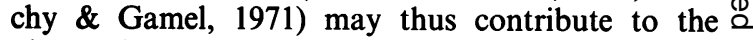
observed plasma cholesterol elevation (Figure 1). §

HDL-cholesterol concentration was unchanged $4 \mathrm{~d} \vec{\circ}$ into the fast, but dropped on the fifth day (Figure 1). These results are in accordance with those found $\vec{\omega}$ during a $10 \mathrm{~d}$ modified fast in man (Wallentin \& $\frac{\text { S }}{8}$ Sköldstam, 1980).

The increase in apo B and the reduction in apo A-I $\stackrel{3}{2}$. levels in plasma correlate with the changes observed $\stackrel{9}{\rightarrow}$ for LDL- and HDL-cholesterol, respectively. The normal values obtained for platelet aggregation after $\vec{v}$ $6 \mathrm{~d}$ of fasting suggest that fasting does not affect ${ }_{\mathcal{W}}$ platelet function and that the relatively small changes in plasma lipid levels cannot affect platelet aggregation.

A marked reduction in VLDL and HDL apo E was found after $9 \mathrm{~d}$ of fasting (Figure 2). Since apo $\mathrm{E}$ is mainly of liver origin (Schaefer et al., 1978), these results may represent changes in the lipoprotein on induced by reduction in some of the liver's activities. Our observation (Table II) of decreased alkaline phosphatase as well as of GOT (which are enzymes of hepatic origin) supports this hypothesis of reduced liver function during fasting in normal subjects.

The elevated plasma lipid levels in non-obese fasted subjects, as opposed to the reduced plasma lipid levels in obese fasted patients, are probably a result of the difference in their tissue lipid content. It might be that in obese normo-lipidaemic subjects the mobilization rate of free fatty acids is lower than in non-obese normo-lipidaemic subjects. Thus, it is suggested that the increased free fatty acid availability to the circulation in the non-obese subjects contributes to enhanced VLDL synthesis and elevated plasma triglyceride levels. In obese subjects, however, reduced free fatty acid mobilization may result in its plasma VLDL utilization and, hence, reduced plasma triglyceride concentration.

The increased plasma apo B levels are probably related to the fact that LDL catabolism is significantly decreased, as has been shown in fasted rabbits (Klauda \& Zilversmit, 1978). In fasted dogs, however, the apo B and apo $\mathrm{E}$ receptors have been induced by prolonged fasting (Mahley et al., 1981), and in fasted rats liver triglyceride accumulation had been observed when perfused with apo E-containing triglyceride emulsions (Quarfordt et al., 1981). It might be that the resistance 
of these animals to atherosclerosis in comparison to rabbits and humans is related to their ability to metabolize the LDL molecules.

In anorexia nervosa, hypercholesterolaemia resulting from elevated plasma LDL levels has also been found (Mordasini et al., 1978), and this probably partially resulted from a hypocaloric metabolic state.

Our study demonstrated plasma lipid elevation after fasting of normal, healthy, non-obese subjects. This resulted from increased plasma concentration of both the triglyceride and the cholesterol carrier lipoproteins.

\section{References}

AVIRAM, M. (1983). Plasma lipoprotein separation by discontinuous density gradient ultracentrifugation in hyperlipoproteinaemic patients. Biochemical Medicine, 30, 111.

AVIRAM, M. \& BROOK, J.G. (1982). The effect of human plasma on platelet function in familial hypercholesterlaemia. Thrombosis Research, 26, 101.

AVIRAM, M. \& BROOK, J.G. (1983a). Platelet interaction with high and low density lipoproteins. Atherosclerosis, 46, 259.

AVIRAM, M. \& BROOK, J.G. (1983b). The effect of blood constituents on platelet function: role of blood cells and plasma lipoproteins. Artery, 11, 297.

AVIRAM, M., BROOK, J.G., LEES, A.M. \& LEES, R.S. (1981). Low density lipoprotein binding to human platelets: role of charge and of specific amino acids. Biochemical and Biophysical Research Communications, 99, 308.

BORN, G.V.R. (1969). Aggregation of blood platelets by adenosine diphosphate and its reversal. Nature, 194, 927.

BROOK, J.G., WINTERSTEIN, G. \& AVIRAM, M. (1983). Platelet function and lipoprotein levels after plasma exchange in patients with familial hypercholesterolaemia. Clinical Science, 64, 637.

BROWNELL, K.D. \& STUNKARD, A.J. (1981). Differential changes in plasma high density lipoprotein-cholesterol levels in obese men and women during weight reduction. Archives of Internal Medicine, 141, 1142.

CONSOLAZIO, C.F., MATOUSH, L.O. \& JOHNSON, H.L. (1967). Metabolic aspects of acute starvation in normal humans (10 days). American Journal of Clinical Nutrition, 20, 672 .

DIETCHY, J.M. \& GAMEL, W.G. (1971). Cholesterol synthesis in the intestine of man: regional differences and control mechanisms. Journal of Clinical Investigation, 50, 872.

ENDE, N. (1962). Starvation studies with special reference to cholesterol. American Journal of Clinical Nutrition, 11, 270.

FAINARO, M. \& SCHAFFER, Z. (1985). Effect of prolonged fasting on plasma lipids, lipoproteins and apolipoprotein B in man. Metabolism, in press.

JACKSON, I. (1969). Effect of prolonged starvation on blood lipid levels of obese subjects. Metabolism, 18, 13.

KLAUDA, H.C. \& ZILVERSMIT, D.B. (1978). Influx of cholesterol into plasma in rabbits with fasting hyperbetalipoproteinaemia. Journal of Lipid Research, 15, 593.

\section{Acknowledgements}

The technical assistance of Mrs Mina Potesman and Mrs Gertrude Dankner as well as that of the chemistry laboratory of our hospital is highly appreciated. The authors thank Drs D. Levin, M. Bulkier, M. Mikelson, A. Swisa, S. Carcabi, M. Bulus, R. Masloj, G. Jayson, Z. Sonis, S. Iserlish, R. Carmeli, Z. Tibi, R. Rubinov, D. Koller, S. Chalil, L. Abud, M. Duitchman, Y. Levy, I. Goldstein, A. Jamid, D. Keret and E. Volfovitch for participating in this study. The secretarial work of Miss Ruth Singer is appreciated.
LAURELL, C.B. (1966). Quantitative estimation of proteins by electrophoresis in agorose gel containing antibodies. Analytical Biochemistry, 15, 45.

LOWRY, O.H., ROSEBROUGH, N.J., FARR, A.L. \& RANDALL, R.S. (1951). Protein measurement with the Folin phenol reagent. Journal of Biological Chemistry, 193, 265.

MAHLEY, R.W., HUI, D.Y., INNERARITY, T.L. \& WEISGRABER, K.H. (1981). Two independent lipoprotein receptors on hepatic membranes of dog, swine and man: apo $\mathrm{B}, \mathrm{E}$ and apo E receptors. Journal of Clinical Investigation, 68, 1197.

MORDASINI, R., KLOSE, G. \& GRETEN, H. (1978). Secondary Type II hyperlipoproteinaemia in patients with anorexia nervosa. Metabolism, 27, 71.

NEWMAN, W.P. \& BRODOWS, R.G. (1983). Insulin action during acute starvation: evidence for selective insulin resistance in normal man. Metabolism, 32, 590.

OLEFSKY, J., REAVEN, G.M. \& FARQUHAR, J.W. (1974), Effect of weight reduction on obesity: studies of lipid and carbohydrate metabolism in normal and hyperlipoproteinaemic subjects. Journal of Clinical Investigation, 53, 64.

QUARFORDT, S.H., SHELBURNE, F.A., MEYERS, W., JAKOI, L. \& HANKS, J. (1981). Effect of apolipoproteins on the induction of hepatic steatosis in rats. Gastroenterology, 80, 149.

RUBIN, L. \& ALADJEM, F. (1954). Serum lipoprotein changes during fasting in man. American Journal of Physiology, 178, 263.

SCHAEFER, E.J., EISENBERG, S. \& LEVY, R.I. (1978). Lipoprotein-apoprotein metabolism. Journal of Lipid Research, 19, 667.

SORBIS, R., PETERSON, B.G. \& NILSON-EHLE, P. (1981). Effects of weight reduction on plasma lipoprotein and adipose tissue metabolism in obese subjects. European Journal of Clinical Investigation, 11, 491.

STOUT, R.W., HENRY, R.W. \& BUCHANAN, K.D. (1976). Triglyceride metabolism in acute starvation: the role of secretion and glucagon. European Journal of Clinical Investigation, 6, 179.

STREJA, D.A., BOYKO, E. \& RABKIN, S.W. (1980). Changes in plasma high density lipoprotein-cholesterol concentration after weight reduction in grossly obese subjects. British Medical Journal, 281, 770.

SWANER, J.C. \& CONNOR, W.E. (1975). Hypercholes- 
terolaemia of total starvation: the mechanism via tissue mobilization of cholesterol. American Journal of Physiology, 229, 365.

WALLENTIN, L. \& SKÖLDSTAM, L. (1980). Lipoproteins and cholesterol esterification rate in plasma during a 10-day modified fast in man. American Journal of Clinical Nutrition, 33, 1925.

WARNICK, R.G. \& ALBERS, J.J. (1978). A comprehensive evaluation of the heparin-manganese precipitation procedure for estimating high density lipoprotein. Journal of Lipid Research, 19, 65.

WARNICK, R.G., MAYFIELD, C., ALBERS, J.J. \& HAZZARD, R.W. (1979). Gel isoelectric focusing method for specific diagnosis of familial hyperlipoproteinemia, Type III. Clinical Chemistry, 25, 279.

WECHSLER, J.G., HUTT, V., WENZEL, H., KLÖR, U. \& DITSHUNEIT, H. (1981). Lipids and lipoproteins during a very low calorie diet. International Journal of Obesity, $\mathbf{5}$, 325.
WOLF, R.N. \& GRUNDY, S.M. (1983). Influence of weight reduction on plasma lipoproteins in obese patients. Arteriosclerosis, 3, 160.

YESHURUN, D., AVIRAM, M., BARAK, K., BARUCH, Y. \& BROOK, J.G. (1982). The effect of prolonged fasting on $C$ lipoprotein concentration and composition in obese $\Rightarrow$ women. Israel Journal of Medical Sciences, 18, 538 (abstr). ज़

ZAK, B. (1977). Cholesterol methodologies: A review. Clinical Chemistry, 23, 1201.

ZIEGENHORN, J. (1975). An improved method for enzymatic $\frac{\overline{\bar{\omega}}}{\mathrm{\omega}}$ determination of serum triglycerides. Clinical Chemistry, 21, 1627.

ZIMMERMAN, J., KAUFMAN, N.A. \& FAINARO, M. (1984). ڤ The effect of weight reduction in moderate obesity on plasma lipoprotein and apolipoprotein levels and on high density lipoprotein composition. Arteriosclerosis, 4, 15. 